\title{
Enantioselective Total Synthesis of Cymoside via a Bioinspired Oxidative Cyclization of a Strictosidine Derivative
}

\author{
Yingchao Dou, ${ }^{[a]}$ Cyrille Kouklovsky, ${ }^{[a]}$ Vincent Gandon, ${ }^{[a, b]}$ and Guillaume Vincent ${ }^{\star[a]}$
}

Dedication ((optional))

\begin{abstract}
The first total synthesis of the caged monoterpene indole alkaloid cymoside is reported. This natural product displays a unique hexacyclic-fused skeleton whose biosynthesis implies an early oxidative cyclisation of strictosidine. Our approach to the furo[3,2$b$ ]indoline framework relied on an unprecedented biomimetic sequence which started by the diastereoselective oxidation of the indole ring into a hydroxyindolenine which triggered the addition of an enol ether and was followed by the trapping of an oxocarbenium intermediate.
\end{abstract}

The very large family of monoterpene indole alkaloids, which encompasses more than 3000 compounds, is biosynthetically derived from an enzyme-catalyzed Pictet-Spengler reaction between secologanin (2), a glycosylated monoterpene, and tryptamine (1) to deliver strictosidine (3). ${ }^{[1]}$ From this point, divergent biosynthetic pathways lead to several sub-families with skeletons of high structural diversity (Scheme 1). The main biosynthetic routes imply a cyclization event between the quinolizidine nitrogen N4 and an aldehyde arising from the deglucosylation of the secologanin subunit. For instance, strictosidine (3) is transformed into 4,21-dehydocorynantheine aldehyde (4) and the corynanthe skeleton through the condensation of the released aldehyde at C21 with N4. Then, oxidative cyclization and/or skeletal rearrangement could occur to produce the yohimban, sarpagan, akuammilan, excelsidine, mavacuran, strychnan, ibogan or aspidosperman alkaloids among others. For instance, we have recently described the bioinspired divergent oxidative cyclization of the geissoschizine (corynanthe) skeleton into the excelsinidine or mavacuran frameworks. ${ }^{[2]}$

In contrast to this general pathway, an oxidative cyclization of strictosidine could also take place as observed from the frameworks of few monoterpene indole alkaloids. ${ }^{[3,4]}$ Among them, cymoside (6) caught our attention due to its unique structure, although no biological activity has been reported. ${ }^{[4]}$ This natural product was isolated by Kritsanida, Grougnet and co-workers from crushed leaves collected from the tree Chimarrhis cymosa (Rubiaceae) in the French Caribbean island Martinique. Cymoside (6) displays an unprecedented caged hexacyclic fusedskeleton which still possesses the glucose moiety and

[a] Mr. Yingchao Dou, Prof. Cyrille Kouklovsky, Prof. Vincent Gandon and Dr. Guillaume Vincent

Univ. Paris Sud, Université Paris-Saclay, CNRS

Institut de Chimie Moléculaire et des Matériaux d'Orsay (ICMMO)

15, rue Georges Clémenceau, 91405 Orsay, Cedex, France E-mail: guillaume.vincent@u-psud.fr

[b] Prof. Vincent Gandon

Laboratoire de Chimie Moléculaire (LCM), CNRS UMR9168 Ecole Polytechnique, Institut Polytechnique de Paris,

Route de Saclay, 91128 Palaiseau cedex (France) encompasses a rare furo[3,2-b]indoline motif. In natural products, the latter is only related to the benzofuro[3,2-b]indoline of phalarine ${ }^{[5]}$ or the furo[3,2-b]indolone of lapidilectin $B$, grandilodine $\mathrm{C}$ and their congeners. ${ }^{[6,7]}$ Biosynthetically, this high degree of complexity was proposed to arise from the intramolecular oxidative coupling between the enol ether of the monoterpene subunit and the indole via oxidation of the latter into hydroxyindolenine intermediate $5 .{ }^{[4]}$

Cymoside (6) appeared to us as a challenging target in relation with our interest in dearomatization of indoles. ${ }^{[8-12]}$ Notably, we have recently developed bioinspired oxidative strategies to access the iso-chromeno[3,4-b]indoline and benzofuro[2,3b]indoline moieties of bipleiophylline. ${ }^{[9]}$ Closer to our target, we reported the synthesis of the benzofuro[3,2-b]indoline framework of phalarine via an oxidative coupling between $\mathrm{N}$-Ac indoles and phenols ${ }^{[10]}$ or an interrupted Fischer indolization. ${ }^{[11]}$ We accessed, as well, the furano[3,2- $b]$ indoline skeleton encountered in cymoside via a [3+2] annulation between $\mathrm{N}-\mathrm{Ac}$ indoles and oxyallyl cations. ${ }^{[12]}$

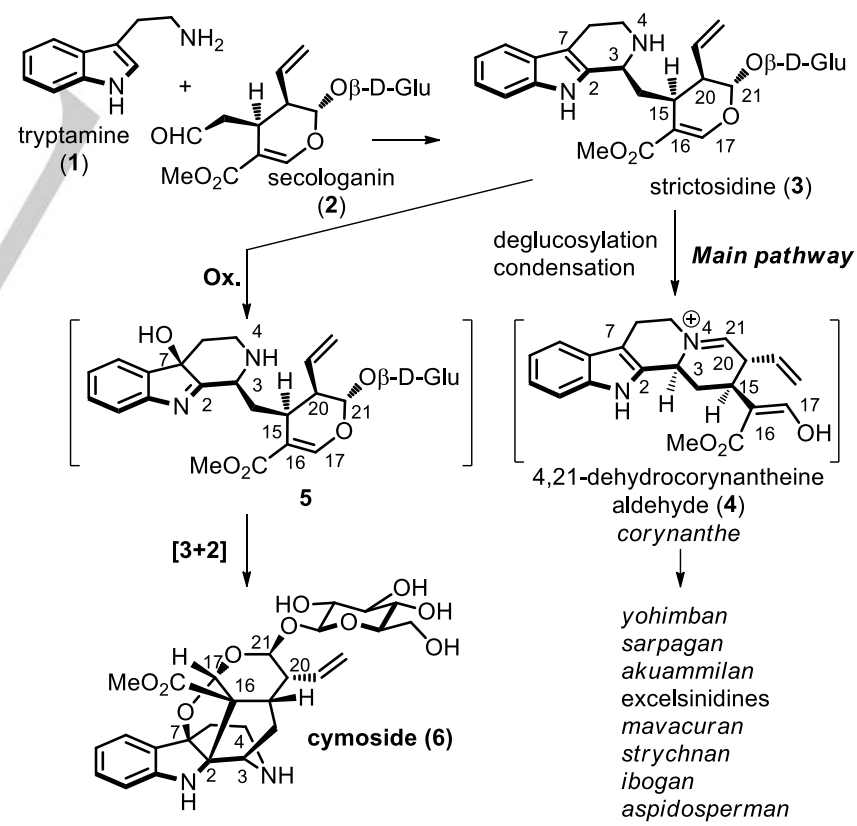

Scheme 1. Biosynthesis of monoterpene indole alkaloids and of cymoside.

In this context, we decided to adopt a bioinspired approach toward cymoside (Scheme 2). We planned to obtain the furano[3,2$b]$ indoline-containing hexacyclic fused-skeleton via an oxidative cyclization of a strictosidine derivative $7 .^{[13,14]}$ Indeed, the latter would arise from the Pictet-Spengler reaction ${ }^{[15]}$ of a secologanin 
derivative $\mathbf{8}$ which would be obtained as described by Tietze three decades ago. ${ }^{[16-18]}$ It involved a domino sequence of a Knoevenagel condensation between aldehyde 9 and protected malondialdehyde $\mathbf{1 0}$ followed by an inverse-demand hetero DielsAlder cycloaddition between generated enal $\mathbf{1 1}$ and enol ether 12. ${ }^{[16 a]}$ Methanolysis, sulfoxide elimination and release of the aldehyde from the dithiane furnished secologanin aglycon $\mathbf{8}$.
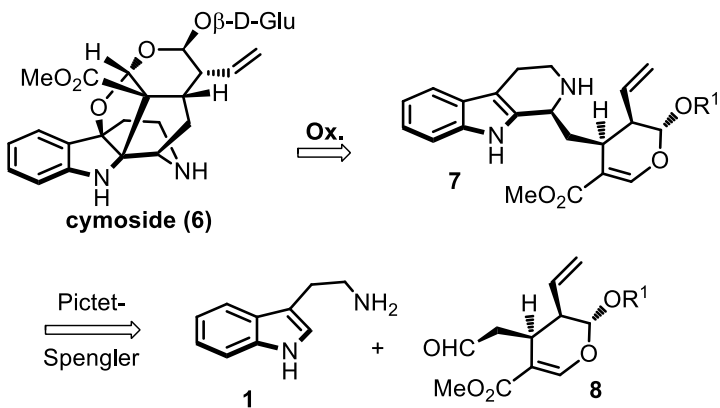

Synthesis of secologanin alycon ethyl ether 8 by Tietze

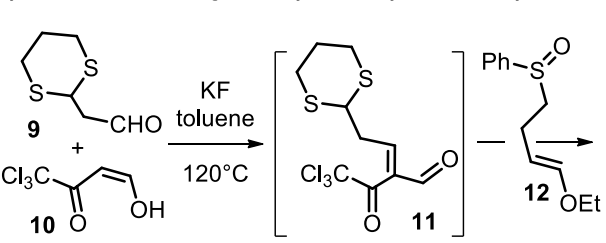

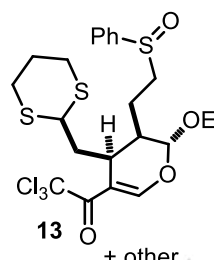

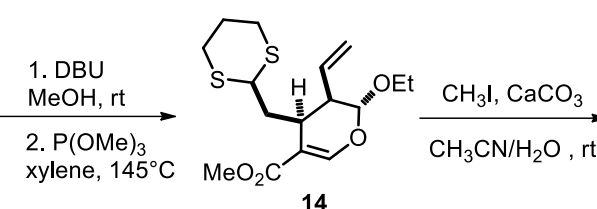

diastereoisomers

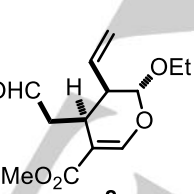

8

Scheme 2. Bioinspired retrosynthesis of cymoside.

In order to assess, the viability of the oxidative cyclization approach, we started to synthesize a simplified analog 17a of secologanin lacking the vinyl substituent (Scheme 3). The PictetSpengler reaction between tryptamine 1 and secologanin analog 15 lacking the vinyl moiety ${ }^{[16 b, c]}$ delivered 17 a,b as a $1: 1$ ratio of epimers and $\mathbf{1 6}$ which aroused from the lactonization of the undesired epimer. The observed diastereoselectivity is in accord with all observations in the literature since only the use of the enzyme strictosidine synthase is able to stereoselectively produce strictosidine derivatives. ${ }^{[15]}$ With 17 in hands, the stage was set to evaluate the key oxidative cyclization. Unfortunately, the desired framework of cymoside could not be obtained despite intensive efforts. With most of the oxidants tried, ${ }^{[14]}$ unidentified over-oxidation products were observed. The free secondary amine N4 appeared to be rather fragile to oxidative conditions. Therefore, we decided to protect it with a para-nosyl group to yield 18a and its epimer 18b as a 1.06:1 mixture. Subsequently, we were pleased to identify oxaziridine $\mathbf{1 9}^{14 \mathrm{~b}}$ in acidic conditions as a suitable oxidant to promote the desired oxidative cyclization of 18a and deliver the intricate fused-hexacyclic skeleton 20 of cymoside in $45 \%$ from the epimeric mixture of $\mathbf{1 8 a} / \mathbf{1 8 b}$ which represent a $88 \%$ yield from the adequate epimer $18 \mathbf{a}^{[19]}$ It is presumed that oxaziridine 19 induced the epoxidation of the
$\mathrm{C} 2=\mathrm{C} 7$ double bond of the indole of $18 \mathrm{a}$ which is followed by a cascade of cyclizations. The removal of the nosyl group is a trivial operation which delivered free secondary amine $\mathbf{2 1}$.

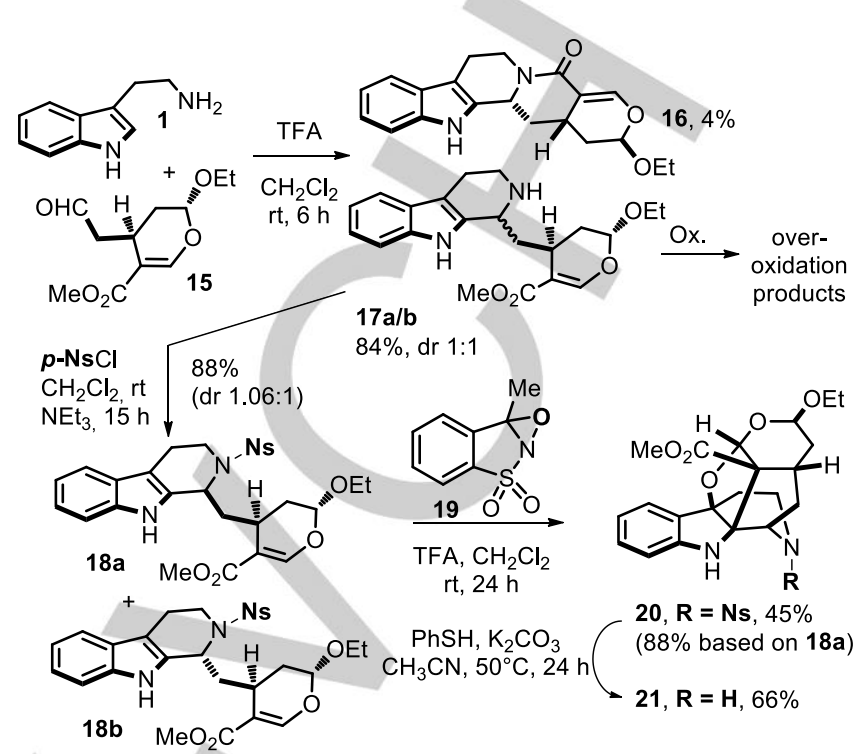

Scheme 3. Development of the key oxidative cyclization on a model substrate.

The arylsulfonyl protecting group of the quinolizidine nitrogen N4 is crucial to allow this complex transformation to happen. Indeed, the nosyl group masks the reactivity of $\mathrm{N} 4$ towards oxidants. Moreover, we postulate that it would also shield one of the face to control the diastereoselectivity of the epoxidation. DFTcomputations were carried out to determine the best possible conformation of 18a (Scheme 4). This analysis shows that to minimize steric interactions between the nosyl group and the dihydropyran substituent at $\mathrm{C} 3$ of $\mathbf{1 8 a}$, the phenyl ring of the nosyl group is forced to lie under the indole ring without $\pi$-staking interactions. The structure is rigidified by an intramolecular hydrogen bond between the carbonyl of the methyl ester and the hydrogen borne by the indolic nitrogen. Consequently, the face encumbered by the nosyl group appears to be blocked and the epoxidation would occur on the less hindered face (Scheme 4). Therefore after opening of epoxide $\mathbf{2 2}$ by the lone pair of the indolic nitrogen, the dihydropyran at C3 and the hydroxyl group at C7 of hydroxyindolenine $\mathbf{2 3}$ are cis to each other which is required to continue the domino cyclization. Accordingly with the biosynthetic hypothesis of Kritsanida and Grougnet, the enol ether could then add to the imine part of $\mathbf{2 3}$ and generate oxocarbenium 24 which could be trapped by the hydroxyl group at $\mathrm{C} 7$, thus completing the furo[3,2-b]indoline moiety of $\mathbf{2 0}$ 


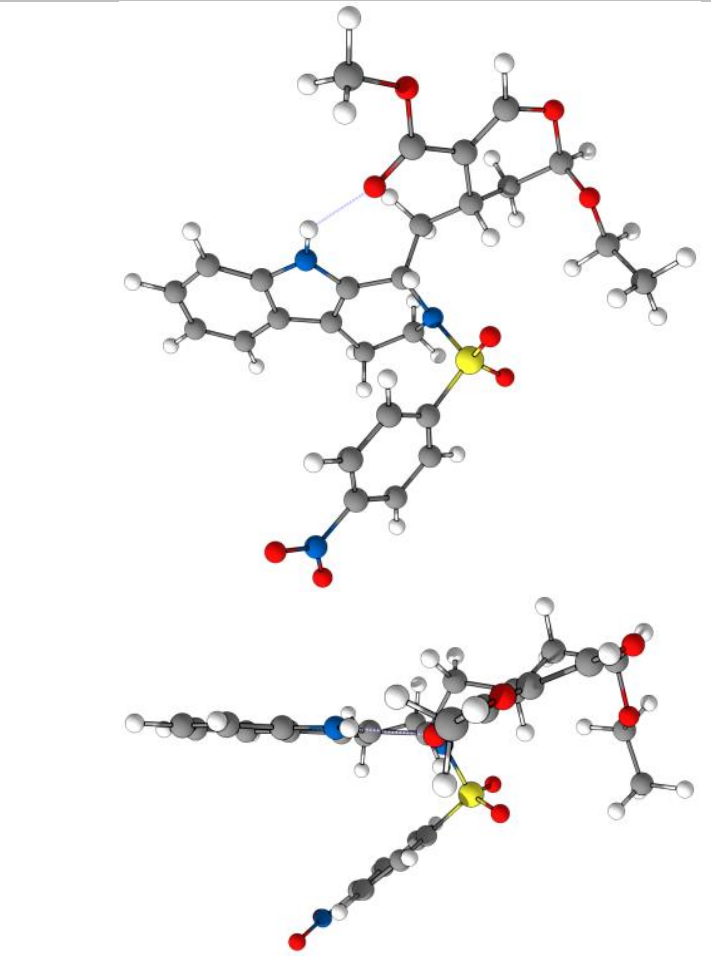

operation would also allow us to separate the two enantiomers of the racemic mixture of 25 since we would use a highly enantioenriched glycosyl reagent. Hydrolysis of the acetal of 25 produced hemiacetal $\mathbf{2 7}$ in a 9:1 mixture of epimers. The Schmidt glycosylation of $\mathbf{2 7}$ with glycosyl trichloroacetimidate $\mathbf{2 8}^{[20]}$ in presence of trifluoroborane yielded the expected protected glycosylated compound 29a in mixture with two minor isomers ${ }^{[21]}$ (ratio $2: 1: 1$ ) as well as the glycosylated product $29 \mathrm{~b}$ of the enantiomer of the cymoside scaffold. Finally, we achieved the first total synthesis of cymoside (6) after the successive removal of the nosyl group from the quinolizidine nitrogen and hydrolysis of the four acetates of the glycosyl moiety in $47 \%$ over two steps from the mixture of $29 \mathbf{a}$ and its isomers. ${ }^{[22,23]}$ It is noteworthy that we were also able to effect this double deprotection on $\mathbf{2 9 b}$ to obtain 30 which is a diastereoisomer of cymoside.

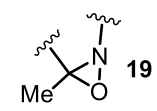

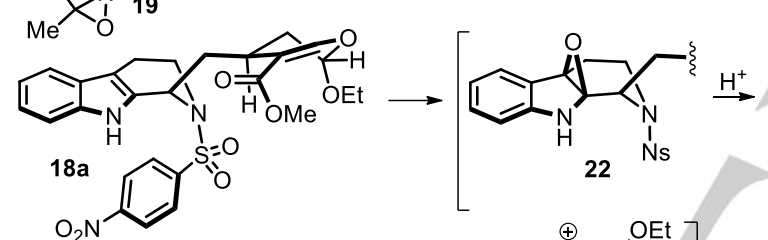

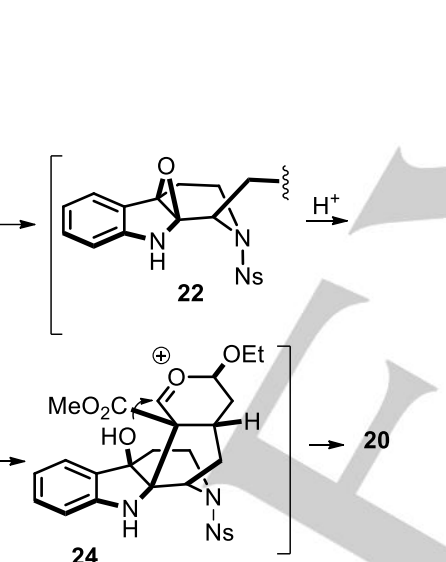

Scheme 4. Bottom and side views of DFT-minimized conformation of $18 \mathbf{a}$ in $\mathrm{CH}_{2} \mathrm{Cl}_{2}$ (Gaussian 09 software package, M06 functional and 6-31G(d,p) basis set for all atoms) and mechanistic hypothesis for the conversion of 18a into 20.

Having established the proof of concept of the key oxidative intramolecular coupling, we directed our efforts towards the total synthesis of cymoside (6) itself. Uneventfully, the Pictet-Spengler reaction of the Tietze secologanin aglycon 8 and tryptamine (1) followed by protection of the secondary amine with a para-nosyl group yielded protected strictosidine aglycon ethyl ether $\mathbf{7 a}$ in a 1.4:1 mixture with its epimer $\mathbf{7 b}$.

Gratefully, the key biomimetic domino sequence of oxidation with oxaziridine 19 and cyclization of strictosidine derivative $7 a$ successfully proceeds very well in presence of the vinyl substituent (Scheme 5). The complete framework 25 of cymoside was thus obtained in $42 \%$ from the epimeric mixture of $7 a / 7 b$ which represents a $72 \%$ yield from $7 a^{\left[{ }^{[19]}\right.}$ Indeed, the ethyl ether aglycon $\mathbf{2 6}$ of cymoside was obtained in $71 \%$ yield after removal of the nosyl group with thiophenol in basic conditions.

In order to achieve the total synthesis of $\mathbf{6}$, the main event remaining was the introduction of the $\beta$-D-glucose moiety. This
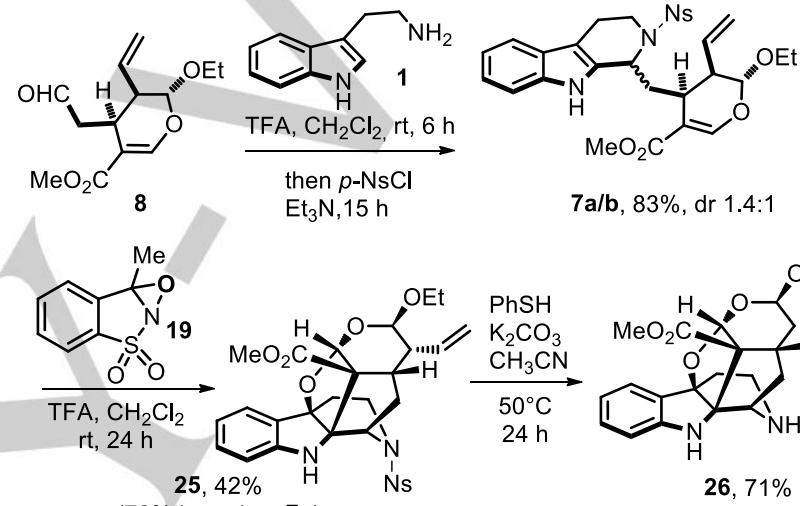
monoterpene alkaloids, the biosynthesis of hexacyclic-fused cymoside (6) involves a unique oxidative cyclization cascade from strictosidine. Inspired by this biosynthetic consideration, we achieved this unprecedented transformation from an adequately protected strictosidne aglycone in presence of an oxaziridine. Key to the success of this biomimetic reaction is the use of a nosyl protecting group of the N4 secondary amine, which masks the reactivity of the latter and directs the facial selectivity of the oxidation of the indole nucleus into a hydroxyindolenine. Addition of the enol ether of the terpenic moiety to this imine was followed by the trapping of the generated oxocarbenium by the hydroxyl to deliver the furo[3,2-b]indoline framework of the natural product. The total synthesis of cymoside (6) was finally achieved via a late stage introduction of the $\beta$-D-glucose.

\section{Acknowledgements}

YD thanks the China Scholarship Council (CSC) for his PhD fellowship. We also gratefully acknowledge the ANR (ANR-15CE29-0001; "Mount Indole"), the Université Paris-Sud and the CNRS for financial support. We thank Dr. Marina Kritsanida and Dr. Raphaël Grougnet from the Faculty of Pharmacy of Université Paris-Descartes for fid data of all NMR of natural cymoside and helpful discussions as well as Dr. Laurent Evanno and Prof. Erwan Poupon from the Faculty of Pharmacy of Université ParisSud and Université Paris Saclay for helpful discussions.

Keywords: Total synthesis • Monoterperne indole alkaloids • Cymoside $\cdot$ Oxidative cyclisation $\cdot$ Furoindoline

[1] For selected reviews on the biosynthesis of monoterpene indole alkaloids: a) S. E. O'Connor, J. J. Maresh, Nat. Prod. Rep. 2006, 23, 532-547; b) L. F. Szabó, Molecules 2008, 13, 1875-1896.

[2] a) M. Jarret, A. Tap, C. Kouklovsky, E. Poupon, L. Evanno, G. Vincent, Angew. Chem. Int. Ed. 2018, 57, 12294-12298; Angew. Chem. 2018 130, 12474-12478; b) M. Jarret, A. Tap, V. Turpin, J.-F. Gallard, C. Kouklovsky, E. Poupon, G. Vincent, L. Evanno, Angew. Chem. Int. Ed. 2019, 58, 9861-9865; Angew. Chem. 2019, 131, 9966-9970.

[3] M. Pinar, M. Hanaoka, M. Hesse, H. Schmid, Helv. Chim. Acta 1971, 54, 15-43.

[4] C. Lémus, M. Kritsanida, A. Canet, G. Genta-Jouve, S. Michel, B. Deguin, R. Grougnet, Tetrahedron Lett. 2015, 56, 5377-5380.

[5] Total syntheses of phalarine: a) C. Li, C. Chan, A. C. Heimann, S. J. Danishefsky, Angew. Chem. Int. Ed. 2007, 46, 1444-1447; Angew. Chem. 2007, 119, 1466-1469; b) J. D. Trzupek, D. Lee, B. M. Crowley, V. M. Marathias, S. J. Danishefsky, J. Am. Chem. Soc. 2010, 132, 85068512; c) H. Ding, D. Y.-K. Chen, Angew. Chem. Int. Ed. 2011, 50, 676679; Angew. Chem. 2011, 123, 702-705; d) L. Li, K. Yuan, Q. Jia, Y. Jia, Angew. Chem. Int. Ed. 2019, 58, 6074-6078; Angew. Chem. 2019, 131, 6135-6139; synthetic studies towards benzofuro[3,2-b]indolines: e) $\mathrm{K}$. Muñiz, J. Am. Chem. Soc. 2007, 129, 14542-14543; f) S. S. K. Boominathan, J.-J. Wang, Chem. - Eur. J. 2015, 21, 17044-17050; g) K Douki, J. Shimokawa, M. Kitamura, Org. Biomol. Chem. 2019, 17, 17271730.

[6] Total syntheses of lapidilectine B and grandilodine C: a) W. H. Pearson, Y. Mi, I. Y. Lee, P. Stoy, J. Am. Chem. Soc. 2001, 123, 6724-6725; b) M. Nakajima, S. Arai, A. Nishida, Angew. Chem. Int. Ed. 2016, 55, 34733476; Angew. Chem. 2016, 128, 3534-3537; c) Y. Gao, M. Fan, Q. Geng D. Ma, Chem. - Eur. J. 2018, 24, 6547-6550; d) F. M. Miloserdov, M. S. Kirillova, M. E. Muratore, A. M. Echavarren, J. Am. Chem. Soc. 2018 140, 5393-5400; synthetic studies towards furo[3,2-b]indolones: e) M Ikeda, T. Uno, K.-I. Homma, K. Ohno, Y. Tamura, Synth. Commun. 1980, 10, 437-449; f) T. Izumi, K. Kohei, S. Murakami, J. Heterocycl. Chem.
1993, 30, 1133-1136; g) T. Kawasaki, K. Masuda, Y. Baba, R. Terashima, K. Takada, M. Sakamoto, J. Chem. Soc. Perkin 1 1996, 729733; h) V. Ramella, Z. He, C. G. Daniliuc, A. Studer, Eur. J. Org. Chem. 2016, 2268-2273.

[7] Selected methods for the synthesis of furo[3,2-b]indoline derivatives: a) S. A. Bonderoff, A. Padwa, Org. Lett. 2013, 15, 4114-4117; b) Y Tokimizu, S. Oishi, N. Fujii, H. Ohno, Angew. Chem. Int. Ed. 2015, 54, 7862-7866; c) S. A. Morris, T. H. Nguyen, N. Zheng, Adv. Synth. Catal. 2015, 357, 2311-2316; d) E. Deruer, S. Canesi, Org. Biomol. Chem. 2017, 15, 3736-3741; e) Z. Xia, J. Hu, Y.-Q. Gao, Q. Yao, W. Xie, Chem. Commun. 2017, 53, 7485-7488.

[8] For a general review on indole dearomatization: S. P. Roche, J.-J. Youte Tendoung, B. Tréguier, Tetrahedron 2015, 71, 3549-3591.

[9] a) D. Lachkar, N. Denizot, G. Bernadat, K. Ahamada, M. A. Beniddir, V. Dumontet, J.-F. Gallard, R. Guillot, K. Leblanc, E. O. N'nang, et al., Nat. Chem. 2017, 9, 793-798; b) N. Denizot, A. Pouilhès, M. Cucca, R. Beaud, R. Guillot, C. Kouklovsky, G. Vincent, Org. Lett. 2014, 16, 5752-5755; c) R. Beaud, R. Guillot, C. Kouklovsky, G. Vincent, Angew. Chem. Int. Ed. 2012, 51, 12546-12550; Angew. Chem. 2012, 124, 12714-12718.

[10] a) T. Tomakinian, R. Guillot, C. Kouklovsky, G. Vincent, Angew. Chem. Int. Ed. 2014, 53, 11881-11885; Angew. Chem. 2014, 126, 1207512079; for related works: b) K. Liu, S. Tang, P. Huang, A. Lei, Nat. Commun. 2017, 8, 775 and ref $5 \mathrm{~d}$.

[11] a) T. Tomakinian, R. Guillot, C. Kouklovsky, G. Vincent, Chem. Commun. 2016, 52, 5443-5446.

[12] A.-S. Marques, V. Coeffard, I. Chataigner, G. Vincent, X. Moreau, Org Lett. 2016, 18, 5296-5299.

[13] For a review on total syntheses of indole alkaloids involving an oxidative coupling: K. Nagaraju, D. Ma, Chem. Soc. Rev. 2018, 47, 8018-8029.

[14] For selected examples of oxidation of indoles into hydroxyindolenine intermediates in total synthesis: a) R. M. Williams, Tomasz. Glinka, Ewa. Kwast, J. Am. Chem. Soc. 1988, 110, 5927-5929; b) S. Liu, J. S. Scotti, S. A. Kozmin, J. Org. Chem. 2013, 78, 8645-8654; c) E. V. MercadoMarin, P. Garcia-Reynaga, S. Romminger, E. F. Pimenta, D. K. Romney, M. W. Lodewyk, D. E. Williams, R. J. Andersen, S. J. Miller, D. J. Tantillo, et al., Nature 2014, 509, 318-324; e) Y. Sun, P. Chen, D. Zhang, M. Baunach, C. Hertweck, A. Li, Angew. Chem. Int. Ed. 2014, 53, 90129016; Angew. Chem. 2014, 126, 9158-9162; f) C. Piemontesi, Q. Wang, J. Zhu, Angew. Chem. Int. Ed. 2016, 55, 6556-6560.

[15] Á. Patthy-Lukáts, Á. Kocsis, L. F. Szabó, B. Podányi, J. Nat. Prod. 1999, 62, 1492-1499.

[16] a) L. F. Tietze, H. Meier, H. Nutt, Chem. Ber. 1989, 122, 643-650; b) L. F. Tietze, H. Meier, H. Nutt, Liebigs Ann. Chem. 1990, 1990, 253-260; c) P. Bernhardt, S. E. O'Connor, Tetrahedron Lett. 2009, 50, 7118-7120.

[17] During the preparation of this manuscript Ishikawa and co-workers reported the first enantioselective synthesis of secologanin: $\mathrm{K}$. Rakumitsu, J. Sakamoto, H. Ishikawa, Chem. - Eur. J. 2019, 25, 89969000.

[18] Racemic syntheses of the secologanin aglycon: a) C. R. Hutchinson, K. C. Mattes, M. Nakane, J. J. Partridge, M. R. Uskoković, Helv. Chim. Acta 1978, 61, 1221-1225; b) M. Nakane, C. R. Hutchinson, J. Org. Chem. 1980, 45, 4233-4236.

[19] While undesired diasteroisomers $\mathbf{1 8 b}$ and $\mathbf{7 b}$ were consumed in the presence of the oxaziridine, we were not able to isolate products arising from the oxidation of these compounds.

[20] a) W. Zhang, M. Ding, J. Li, Z. Guo, M. Lu, Y. Chen, L. Liu, Y.-H. Shen, A. Li, J. Am. Chem. Soc. 2018, 140, 4227-4231; b) I. K. Mangion, D. W. C. MacMillan, J. Am. Chem. Soc. 2005, 127, 3696-3697.

[21] We believe that one of them is epimeric to $30 \mathrm{a}$ or $\mathbf{3 0 b}$ at the anomeric position ( $\alpha$-D-glucose instead of $\beta$-D-glucose), while the second one might be an epimer of $\mathbf{3 0 a}$ or $\mathbf{3 0 b}$ at the $\mathrm{C} 21$ position.

[22] Despite the significant difference in the optical rotation $\left([\alpha]^{\mathrm{D}}+190\right.$, c 0.011 in $\mathrm{MeOH}$ for the natural product and $[\alpha]^{\mathrm{D}}-26, \mathrm{c} 0.015$ in $\mathrm{MeOH}$ for our synthetic product), all the 1D and 2D NMR data as well as the HRMS data of our synthetic product are in accord with the data reported for natural cymoside. Unfortunately, natural cymoside is not available at the present time.

[23] In the isolation paper (ref 4), it was hypothesized that cymoside was isolated as an ammonium salt via protonation of the $\mathrm{N} 4$ secondary amine. 
WILEY-VCH

Our synthetic cymoside was not obtained as an ammonium salt, since it was isolated after a basic aqueous work-up. Since all the $1 \mathrm{D}$ and $2 \mathrm{D}$

NMR data of the natural and synthetic cymoside are concordant, we believe that the natural cymoside was isolated as a free base and not as an ammonium salt. 
